\title{
Benefits Associated with Experiential and Material Purchases May Depend on Culture
}

\author{
Pooya Razavi ${ }^{1}$, Hadi Shaban-Azad ${ }^{2}$, Wen Jia Chai ${ }^{3}$, Jia Wei Zhang ${ }^{4}$, Ngoc-Han Nguyen ${ }^{5}$, \\ Ryan T. Howell ${ }^{5}$
}

${ }^{1}$ University of Oregon, Eugene, OR, USA

${ }^{2}$ University of Tehran, Iran

${ }^{3}$ Universiti Sains Malaysia, Kota Bharu, Kelantan, Malaysia

${ }^{4}$ University of Memphis, TN, USA

${ }^{5}$ San Francisco State University, CA, USA

Corresponding author: Pooya Razavi

匈 pooyar@uoregon.edu

This paper is published at the Social Psychological and Personality Science (SPPS). The present post-print may not replicate the final version published in the journal. It is not the copy of record and may differ from the final published version, which is available here.

The Online Supplement document, data, codebook, R-code, and the analyses output can be found at https://osf.io/n39gj/.

APA Citation:

Razavi, P., Shaban-Azad, H., Chai, W. J., Zhang, J. W., Nguyen, N. H., \& Howell, R. T. (2020). Benefits Associated with Experiential and Material Purchases May Depend on Culture. Social Psychological and Personality Science, 11(5), 626-637. 


\begin{abstract}
Spending money on experiences, compared to materials, is often associated with more happiness. This experiential advantage, however, is developed based on samples from Western cultures. To investigate the boundaries of this effect, we studied participants from three divergent cultures (Iran, Malaysia, and the US; $N=1718$ ), and examined the benefits of different purchase types across materialexperiential and solitary-social dimensions. Results indicated a cross-culturally robust experiential advantage in terms of affiliative outcomes (i.e., positive other-focused emotions and relational enhancement), even when we accounted for the sociality of the purchases. However, the results were less consistent with the experiential advantage in terms of happiness and self-focused outcomes (i.e., self-focused emotions and self-elevation). Interestingly, experiential-solitary purchases were associated with stronger self-focused benefits among Iranians. We discuss possible explanations for this effect and offer recommendations for future research. Data and analysis code are publicly available at https://osf.io/n39gj/.
\end{abstract}

Keywords: experiential advantage, spending money, happiness, emotions, culture

In a seminal critique of social psychology, Rozin (2001) pointed out the surprising scarcity of research on major domains of social life such as "[...] leisure, sports, music, drama (theatre), money, or work" (p. 13). Since then, many of these domains have received substantial attention from researchers, leading to a growing literature. One such area is the research on spending money and happiness. Across a multitude of studies, researchers have found that spending money on experiences, compared to materials, leads to greater levels of happiness and satisfaction, an effect often referred to as the experiential advantage (Dunn \& Weidman, 2015). Understandably, this effect has been well-publicized beyond psychology journals - upon googling the phrase "materials vs. experiences," one will receive a plethora of advice to spend money on experiences as a way to increase happiness (e.g., The Atlantic (Hamblin, 2014, October 7), Forbes (Pozin, 2016, March 3), and The Guardian (Usborne, 2017, May 13)).
Despite its growth and popularity, the literature on the experiential advantage is susceptible to a second critique noted by Rozin (2001); most of the studies are based on samples from Western cultures, which represent "less than $10 \%$ to $15 \%$ of the populations on the face of the earth" (p. 13). As such, it is not clear whether the experiential advantage is generalizable beyond the Western, Educated, Industrialized, Rich, and Democratic (WEIRD; Henrich, Heine, \& Norenzayan, 2010) societies. Consequently, in a thorough review of the field, Dunn and Weidman (2015) have proposed that an important next step is to expand the science of spending beyond WEIRD samples. One goal of the present research is to address this gap by examining the consequences of different types of purchases among diverse samples from Iran, Malaysia, and the US.

Informed by the literature on crosscultural variability in concepts related to self and well-being (Kito, Yuki \& Thompson, 2017; 
Markus \& Kitayama, 1991), we made methodological choices that can capture the consequences of experiences vs. materials in different domains. Importantly, we used a design that allows for examining the experiential advantage while accounting for the social-solitary dimension of the purchase (Caprariello \& Reis, 2013). Furthermore, we discuss the necessity of cross-culturally examining aspects of well-being beyond happiness, and consequently measure emotions and cognitive evaluations associated with purchases while distinguishing between the self- and other-focused dimensions of these outcomes. In the following sections, we discuss the theoretical foundations of the present research which informed the decisions concerning study design, sampling, and choice of outcomes.

\section{Money for Happiness}

From concert tickets to trendy clothes, much of a person's discretionary income is spent with one specific goal: to be happy (Lebergott, 1993). This attempt to exchange money for happiness, however, is not always successful (Dunn, Gilbert \& Wilson, 2011)the outcome seems to be dependent on the type of purchase one makes. For example, some studies suggest that stronger materialistic values and a tendency to prioritize material possessions (i.e., tangible purchases kept in one's possession; Van Boven \& Gilovich, 2003) is associated with lower well-being (Kashdan \& Breen, 2007; Pandelaere, 2016), higher levels of depression and anxiety, and declined satisfaction with interpersonal relationships (see Kasser, 2016, for a review). In contrast, money spent on experiential purchases (i.e., purchases providing life experiences that one lives through and walks away with a memory) has been shown to yield more happiness compared to material possessions (Carter \& Gilovich, 2010; Millar \& Thomas, 2009; Nicolao, Irwin \& Goodman, 2009).

Several mechanisms have been proposed to account for this experiential advantage. First, experiential purchases provide more happiness through satisfaction of the fundamental need for relatedness (Howell \& Hill, 2009). Experiences (compared to materials) often have a stronger affiliative dimension. In fact, Caprariello and Reis (2013) demonstrated that when participants spontaneously write about a purchase, the material purchases are approximately three times more likely to be solitary, and the experiential purchases are twice more likely to be social. Importantly, using a study design similar to the present research, Caprariello and Reis (2013) demonstrate that when controlling for the sociality of the purchases, the experiential advantage is mostly attenuated and sometimes reversed. Second, people generally associate their experiences more closely to their identity, compared to the possessions they own (Carter \& Gilovich, 2012). Third, compared to material items for which people sometimes engage in invidious comparisons and counterfactual thinking, experiential purchases are less often subject to social comparison and rumination, due to the difficulty in placing a tangible or comparable value on subjective experiences (Carter \& Gilovich 2010).

Studies testing the moderators of the experiential advantage demonstrate that the advantage is not experienced by everyone. For example, Van Boven and Gilovich (2003) found that, in contrast to those in the middleto-higher social class, among those with lower income or lower education levels, experiential advantage was either absent or reversed (also 
see Lee, Hall, \& Wood, 2018). Furthermore, Millar and Thomas (2009) found that people who hold stronger materialistic values report similar levels of happiness for both material and experiential purchases (cf. Nicolao, Irwin \& Goodman, 2009). These moderating variables (i.e., resource availability and materialist values) are known to vary crossculturally, which demonstrates the importance of testing the boundaries of this effect on more diverse samples.

\section{Beyond WEIRD: The Need for Diversity}

Concerns about the homogeneity of samples from which psychological theories are generated has been repeatedly expressed over the past two decades (e.g., Arnett, 2008; Henrich et al., 2010), with recent reviews suggesting the issue is still widespread (Medin, Ojalehto, Marin, \& Bang, 2017; Salari Rad, Martingano, \& Ginges, 2018). In the experiential buying literature, a thorough examination by Dunn and Weidman (2015) showed that $87 \%$ of the studies relied on US student samples or Amazon's Mechanical-Turk participants, and none tested for cross-cultural differences (though 4\% included international participants). This heavy reliance on a limited range of US samples raises concerns about the universality of the experiential advantage. Norenzayan and Heine (2005) recommend that one way to examine universality is to investigate a phenomenon in two or three populations that are highly divergent in various dimensions including "social practices, philosophical traditions, language, geography, socioeconomic status, literacy, and level of education" (p. 767). In-line with this approach, we examine the experiential advantage in three samples from cultures that vary in all the previously mentioned dimensions (see Table 1).

We considered alternative predictions about experiential advantage across cultures. On the one hand, one might expect crosscultural variability in the experiential advantage considering the global variations in materialistic values (Saucier et al., 2015) and how much emphasis cultures put on possessions (Koo \& Suh, 2015). For instance, in a poll of 20 countries (IPSOS, 2013), a large proportion of respondents from China and India believed that their possessions are the measure of their success $(71 \%$ and $58 \%$, respectively), as opposed to only $21 \%$ of the US participants who endorsed such belief. Furthermore, while research on Western samples demonstrates a negative relation between materialism and well-being (e.g., Kasser, 2016), this is not always the case when examining Eastern samples (Wong, Rindfleisch, \& Burroughs, 2003).

On the other hand, it is possible that experiential advantage replicates beyond the US because the underlying mechanisms contributing to the benefits of experiential spending are "existential universals" (see Norenzayan \& Heine, 2005). For example, the need for relatedness and its role in human motivation has been documented beyond Western populations, including in Malaysia (e.g., Church et al., 2013) and in Iran (Hejazi, Salehnajafi, \& Amani, 2015). Similarly, social comparison, another important mediator of experiential advantage, has been demonstrated to influence psychological processes in various cultural contexts, including gender stereotypes in Malaysia (Guimond et al., 2007) and academic achievement in Iran (Hassaskhah \& Jahedi, 2015). 
Table 1.

Country-level Indices of Relevant Cultural V ariables, Well-being, and Economic Resources

\begin{tabular}{|c|c|c|c|c|c|}
\hline & Unit & Iran & Malaysia & US & Source \\
\hline \multicolumn{6}{|l|}{ Cultural Variables } \\
\hline Collectivism-Individualism ${ }^{1}$ & mean score & 41 & 26 & 91 & (Hofstede \& Hofstede, 2010) \\
\hline Autonomy-Embeddedness ${ }^{2}$ & z-score & 0.98 & 1.40 & -0.28 & (Schwartz, 1994; Schwartz, 2006) \\
\hline Tightness-Looseness ${ }^{3}$ & mean score & 31.5 & - & 67.9 & $(\mathrm{Uz}, 2015)$ \\
\hline Looseness-Tightness ${ }^{4}$ & mean score & - & 11.8 & 5.1 & (Gelfand et al., 2011) \\
\hline Fear of happiness & z-score & -0.43 & 0.20 & -0.38 & (Joshanloo et al., 2014) \\
\hline Religiosity & mean score & 82.5 & 90 & 65 & (Joshanloo \& Gebauer, in press) \\
\hline \multicolumn{6}{|l|}{ Well-being } \\
\hline Happiness & global rank & 106 & 54 & 15 & (Helliwell, Layard, \& Sachs, 2018) \\
\hline Life satisfaction & mean score & 4.96 & 5.92 & 7.24 & (Joshanloo, 2018) \\
\hline Perceived social support & global rank & 143 & 78 & 36 & (Helliwell, Layard, \& Sachs, 2018) \\
\hline \multicolumn{6}{|l|}{ Economic resources } \\
\hline GDP per capita & US\$ & 5627.75 & 10117.57 & 59927.93 & (The World Bank Data, 2019a) \\
\hline Educational attainment ${ }^{5}$ & $\%$ & 23.06 & 18.84 & 43.51 & (The World Bank Data, 2019b) \\
\hline Consumption expenditure ${ }^{6}$ & US\$ & 2720.22 & 6297.76 & 36965.62 & (The World Bank Data, 2019c) \\
\hline
\end{tabular}

Notes. ${ }^{1}$ Higher scores on this dimension indicates stronger culture-level individualistic tendency. ${ }^{2}$ Lower scores indicate stronger cultural autonomy (i.e., the extent to which individuals are perceived as autonomous members and encouraged to express feelings and preferences). ${ }^{3}$ Higher scores indicate stronger societal norms and lower tolerance for non-conforming behavior (i.e., tightness). ${ }^{4}$ Higher scores indicate weaker social norms and higher tolerance for non-conforming behavior (i.e., looseness). ${ }^{5}$ The percentage of the population above the age of 25 (in 2016) that at least completed short-cycle tertiary education. ${ }^{6}$ Household spending (per capita) on all goods and services. 
A third possibility, which is our stance, is that experiences and materials might be beneficial in different domains, some of which are universal and others are culture-specific. For example, the affiliative properties of experiences may lead to relational benefits whereas the sense of achievement associated with a material purchase could elicit a feeling of pride and self-worth. Consequently, we included outcome variables, other than happiness, that allow us to capture such nuances.

\section{Beyond Happiness}

The experiential advantage is often discussed in terms of happiness. From a crosscultural perspective, it is beneficial to include a wider range of outcomes for two reasons: First, cultures vary on how much they value happiness (Ji, Nisbett, \& Su, 2001)—while the members of some Western cultures may experience a "pressure" to pursue happiness (Mauss et al., 2012), there can be an "aversion" to higher levels of happiness in some nonWestern contexts (Joshanloo \& Weijers, 2014). Second, cultures differ in their definitions of happiness (Oishi, Graham, Kesebir, \& Galinha, 2013), often assigning different weights in their folk theories of happiness to social ties vs. personal pleasures and achievements (Pflug, 2009; Uchida \& Kitayama, 2009).

Consequently, inspired by culturallyinformed theories of subjective well-being (Diener, Oishi, \& Lucas, 2003), we extended the range of outcomes examined in relation to purchases and included participants' emotional experiences and cognitive evaluations of the impact of their spending on their lives. Furthermore, since the concept of self and how it relates to others is highly variable across cultures, with important implications for domains such as life satisfaction (Suh, 2000; Uchida, Kitayama, Mesquita, Reyes, \& Morling, 2008), in our outcome measures we distinguish between self-focused vs. otherfocused emotions and cognitive evaluations of the purchase.

\section{Study Overview}

The present study aims to address two primary research questions: (a) Does the experiential advantage generalize beyond WEIRD samples? (b) What are the emotional and cognitive evaluations associated with different purchase types, and how universal or culture-specific are these outcomes? To examine these questions, we made theorydriven decisions concerning sampling and methodology. The samples were chosen based on accessibility and, as Norenzayan and Heine (2005) recommend, a plan to achieve high divergence in a wide range of relevant constructs. The three cultures are highly diverse in terms of access to resources, ideological and social norms related to materialistic values (Mehran, 1989; Ong, Kamaruddin, Bulathsinhalage, \& Seneviratne, 2013), and established cultural dimensions such as individualism-collectivism (see Table 1). The considerable divergence among these samples makes them good candidates for a "severe test" of the experiential advantage hypothesis (Dienes, 2008; Mayo, 2010). In deciding the design features of the study, our goal was to control for the social (vs. solitary) aspect of the purchases across cultures in order to facilitate the cross-cultural comparisons of the experiential advantage. As such, we chose Caprariello and Reis's (2013) 2 X 2 structure in which the material-experiential dimension is crossed with the solitary-social dimension. 
The two non-US samples in this study are understudied, even within the cross-cultural literature (Veillard, 2017). Consequently, we did not generate culture-specific hypotheses. Instead, we planned to test the experiential advantage as it is documented in the US in all three cultures with the methodological sensitivity to discover cross-cultural variations and similarities (Rozin, 2001). To capture both culture-specific and universal outcomes associated with purchases, in addition to happiness, we examined self-focused (e.g., pride) and other-focused (e.g., gratitude) emotions, as well as cognitive evaluations of the impact of the purchase on different domains of life, categorized as self-elevation (e.g., "reflection of one's identity") and relational enhancement (e.g., "improving one's friendships").

\section{Method}

\section{Participants}

Sample size determination. A review of seven studies on the primary effect of interest (i.e., a comparison of experiences vs. materials; Carter \& Gilovich, 2010; Howell \& Hill, 2009; Millar \& Thomas, 2009; Pchelin \& Howell, 2014; Van Boven \& Gilovich, 2003; Zhang, Howell, Caprariello, \& Guevarra, 2014) revealed effect sizes (Cohen's $d$ ) ranging from 0.25 to $0.57(M=0.46, M d n=0.49)$. Consequently, we based our calculations on a small-to-moderate effect size of $d=0.35$. For this effect size, a minimum sample of 428 subjects is needed to obtain 95\% power (Faul, Erdfelder, Buchner, \& Lang, 2009). Since Caprariello and Reis (2013) has shown that specifying the solitary-social dimension of the purchase reduces participants' compliance, we set our target sample size to be a minimum of 500 per country. After collecting half of the sample in Iran, a review of completion rates indicated an approximate $20 \%$ attrition, which might be due to higher incidence of disruptions in the internet connection ${ }^{1}$. To compensate for this issue and ensure that the target statistical power is achieved, a proportionally larger sample was collected from Iran.

US sample. Undergraduate psychology students $\left(n=516, M_{a g e}=21.08, S D_{a g e}=5.61\right.$; $72.3 \%$ female, $26.2 \%$ male) at a public university in the southern US completed the study online in exchange for course credit. Participants identified as Caucasian (46.5\%), African American (33.6\%), Asian/Asian American (6.1\%), Hispanic (5.7\%), more than one ethnicity (5.5\%), Middle Eastern (1.6\%), and other $(1.2 \%)$. Based on responses on the MacArthur scale of subjective social status (Adler \& Stewart, 2007), 43.2\% identified as middle class (ladder rungs five and six), 20.7\% identified as lower-to-middle class (rungs one to four), and $35.4 \%$ as middle-to-higher class (rungs seven to ten).

Iranian sample. Community adults $(n=$ 670, $M_{\text {age }}=32.45, S D_{\text {age }}=9.52 ; 50.6 \%$ female, $24.0 \%$ male) who learned about the study through popular socio-cultural channels on the Telegram app. ${ }^{2}$ completed the study online in exchange for personality feedback. Of the 490 participants who reported their education level, $43.5 \%$ were undergraduate students or had a bachelor's degree, $42.3 \%$ were graduate students or had a graduate degree, and the remaining $(14.1 \%)$ had a high school diploma, pre-university, or an associate degree. To avoid any potential cultural sensitivity, ethnicity data were not collected from this sample. Twentyseven percent identified as middle class, $11.5 \%$ identified as lower-to-middle class, and 36.9\% as middle-to-higher class. 
Malaysian sample. Undergraduate psychology students $\left(n=532, M_{\text {age }}=22.98\right.$, $S D_{a g e}=5.07 ; 77.1 \%$ female, $19.4 \%$ male) at a private university in Kuala Lumpur completed the study in pen-and-paper mode in exchange for course credit or a chance to participate in a raffle. Participants identified as Chinese (78.8\%), Indian (9.5\%), Malay $(8.6 \%)$, and other $(3.1 \%)$, and completed the study in English, which is one of Malaysia's official languages of tertiary education (Puteh, 2010). Majority (54.4\%) identified as middle class, $18.4 \%$ identified as lower-to-middle class, and $23.7 \%$ as middle-to-higher class.

\section{Procedure and Materials}

In a 2 (experiential vs. material) X 2 (social vs. solitary) between-subjects design, participants were randomly assigned to one of four conditions (i.e., material-solitary, materialsocial, experiential-solitary, experiential-social). The instructions required participants to recall and write about a non-essential purchase that they made with the intention of advancing their happiness. Depending on the experimental condition, participants were asked to write about either a material ("a physical, tangible object") or an experiential ("a life experience or event that did not result in a possession of a physical object, but a memory") purchase. Furthermore, instructions also specified the solitary (e.g., "a material possession to use by yourself”) or social (e.g., "a material possession to use with at least one other person") aspect of the purchase. The instructions were inspired by past studies in the US (e.g., Caprariello \& Reis, 2013; Van Boven \& Gilovich, 2003). However, to ensure cultural and linguistic equivalence, we consulted seven cultural informants from Iran and Malaysia and adjusted the instructions based on their feedback. The final prompts were identical in all countries, except for the price range ${ }^{3}$ that was provided using each country's currency (see Online Supplement).

Positive emotional experience. After writing about the purchase, participants rated their positive emotional experience while reviewing the memory of their purchase using the positive items from Impett et al. (2010) that includes self-focused emotions (4 items; $\alpha=$ 0.78; e.g., “proud/good about myself') and other-focused emotions ( 4 items; $\alpha=0.80$; e.g., "grateful/appreciative/thankful"). Participants reported how much they experienced each emotion on a 5 -point scale ("Not at all" to " $A$ lot'). For sample-specific internal consistency coefficients, see Table 5.

Instant happiness. A single item (i.e., "Compared to how you felt right before you spent your money, how much happier were you right after your purchase?") was used to measure participants' immediate happiness from the purchase (response anchors for happiness items: $1=$ "Not at all"; $4=$ "Moderately"; 7 = "Very much").

Overall happiness. Two items (e.g., "How much has this purchase contributed to your overall life happiness?”) measured participants' evaluation of the contribution of the purchase to their well-being $(\alpha=0.90)$.

Cognitive evaluations. Participants completed eight evaluative items that were developed based on potential effects of purchases on different life domains, including psychological need satisfaction (Deci \& Ryan, 1985; Johnston \& Finney, 2010). Some items captured the self-focused goals associated with purchases (e.g., "This purchase reflected my true identity"), and others reflected relational goals (e.g., "This purchase helped me make new friends or strengthen existing 
friendships.”). A Principal Component Analysis (PCA) of the items supported this two-component structure: Self-elevation (four items; $\alpha=0.82$ ) and Relational-enhancement (four items; $\alpha=0.76$; see Table 2).

Table 2.

Results of the PCA of the General Evaluations Items

Item

Component 1 Component 2

This purchase made me feel curious, inquisitive, interested.

$\mathbf{0 . 9 0}-0.08$

This purchase made me feel awe, wonder, and amazement.

$\mathbf{0 . 8 8}-0.06$

This purchase increased my knowledge in one or more areas.

$\mathbf{0 . 8 1} \quad 0.04$

This purchase reflected my true identity.

0.55

0.20

This purchase helped me make new friends or strengthen

0.00

0.84

existing friendships.

This purchase made me feel more connected to people.

0.04

0.81

This purchase made me feel less lonely.

$-0.08$

0.73

This purchase created positive memories for me.

0.32

0.52

Note. Loadings above 0.40 are in bold. Oblimin rotation with Kaiser normalization was used. The KMO's measure of sampling adequacy was .84, and extraction communalities ranged from .45 to .75 . The two components explained $63.05 \%$ of sums of squared loadings and were correlated at .54 . These results are based on PCA on the whole sample. PCA and CFA results for each sample, as well as the results of the measurement invariance analyses are reported in the Online Supplement.

Negative outcomes. We included three negative outcomes for exploratory purposes: negative self-focused emotions (4 items; $\alpha=$ 0.70 ; e.g., “sad/depressed/down”), negative other-focused emotions ( 2 items; $\alpha=0.56$; e.g., "criticized/blamed"), and regret about the purchase ( 3 items; $\alpha=0.68$ ). These outcomes had negligible variability (e.g., the median response to all negative emotion items was one (i.e., "not at all")), suggesting that the present design, like most studies in this literature, elicited primarily successful purchases (Nicolao, Irwin, \& Goodman, 2009). As such, these outcomes are not reported any further; however, the data is publicly available for further investigation.

Purchase characteristics. Participants were given a list of 20 purchase categories (e.g., "Beauty products") and asked which one best describes their purchase. Furthermore, as a manipulation check, participants reported the extent to which they considered their purchase to be non-essential (1: "Absolutely essential"; 5: "Completely non-essential") and the extent to which they considered the purchase to be material or experiential (1: "Only material"; 5: "Only experiential"). Next, participants reported the price and the time elapsed since the purchase.

\section{Results}

Data exclusion. Prior to analyses, two researchers reviewed all the purchase narratives and, following predetermined rules, excluded the cases that did not follow instructions ${ }^{4}$. Narratives were excluded if both researchers agreed that (a) the narrative does not report a purchase, or (b) the reported purchase is not a 
non-essential purchase (e.g., paying the rent), or (c) there is information in the narrative that deems the purchase inconsistent with the social-solitary or material-experiential dimension of the instructions (e.g., a narrative describing a trip with a group of friends written by a participant assigned to the experientialsolitary condition). Data exclusion decisions were reviewed by a third researcher outside the author team to ensure that the decisions are justified. Overall, $10.8 \%$ of the 1718 observations were excluded. The exclusion rates did not differ across samples (Malaysia: 10.9\%, Iran: $9.3 \%$, US: $12.6 \%, \chi^{2}(2, n=1718)$ $=3.41, p=.182)$. However, similar to Caprariello and Reis (2013), non-compliance rates were significantly higher for the experiential-solitary $(21.9 \%)$ and materialsocial $(10.8 \%)$ conditions compared to material-solitary $(5.0 \%)$ and experiential-social $(5.2 \%)$ conditions $\left(\chi^{2}(3, n=1718)=84.42, p<\right.$ $.001)$ - an important caveat to consider when interpreting the following results (West \& Sagarin, 2000). Results without any data exclusion have a similar pattern (see Online Supplement).

Purchase characteristics. A summary of the purchase characteristics is presented in Table 3. Importantly, median purchase price was 89,000 Tomans in Iran (Winsorized $S D=$ 232,936), RM76.45 in Malaysia (Winsorized SD $=130.10$ ), and $\$ 50.00$ in the US (Winsorized $S D=72.47$ ). For examples of purchases in each country, and a visual representation of purchase categories, see the Online Supplement. The price of the different types of purchase was not significantly different in Iran, but was so in Malaysia and the US where participants' reported material purchases (especially material-solitary ones) were more expensive than experiential purchases.
However, controlling for price (standardized within each country) in the main analyses did not influence the results (see https://osf.io/n39gj/). Median time elapsed since purchase was 21 days (Winsorized $S D=$ 34 ), and there was no significant difference between conditions (Table 3) or countries (Welch's $F(2,924.4)=2.82, p=.060$ ).

A comparison of participants' ratings of how material or experiential they consider the purchase to be indicated that, as expected, those in the experiential condition rated the purchase as more experiential $(d=1.82)$. Finally, participants' self-ratings of how nonessential the purchase was indicated that the purchases were generally considered to range from partly to completely non-essential $(M=$ 3.72, $M d n=4, S D=1.34)$. Within this range, experiential-social purchases were perceived as more non-essential than other purchases (Table 3). 
Table 3.

Purchase Characteristics

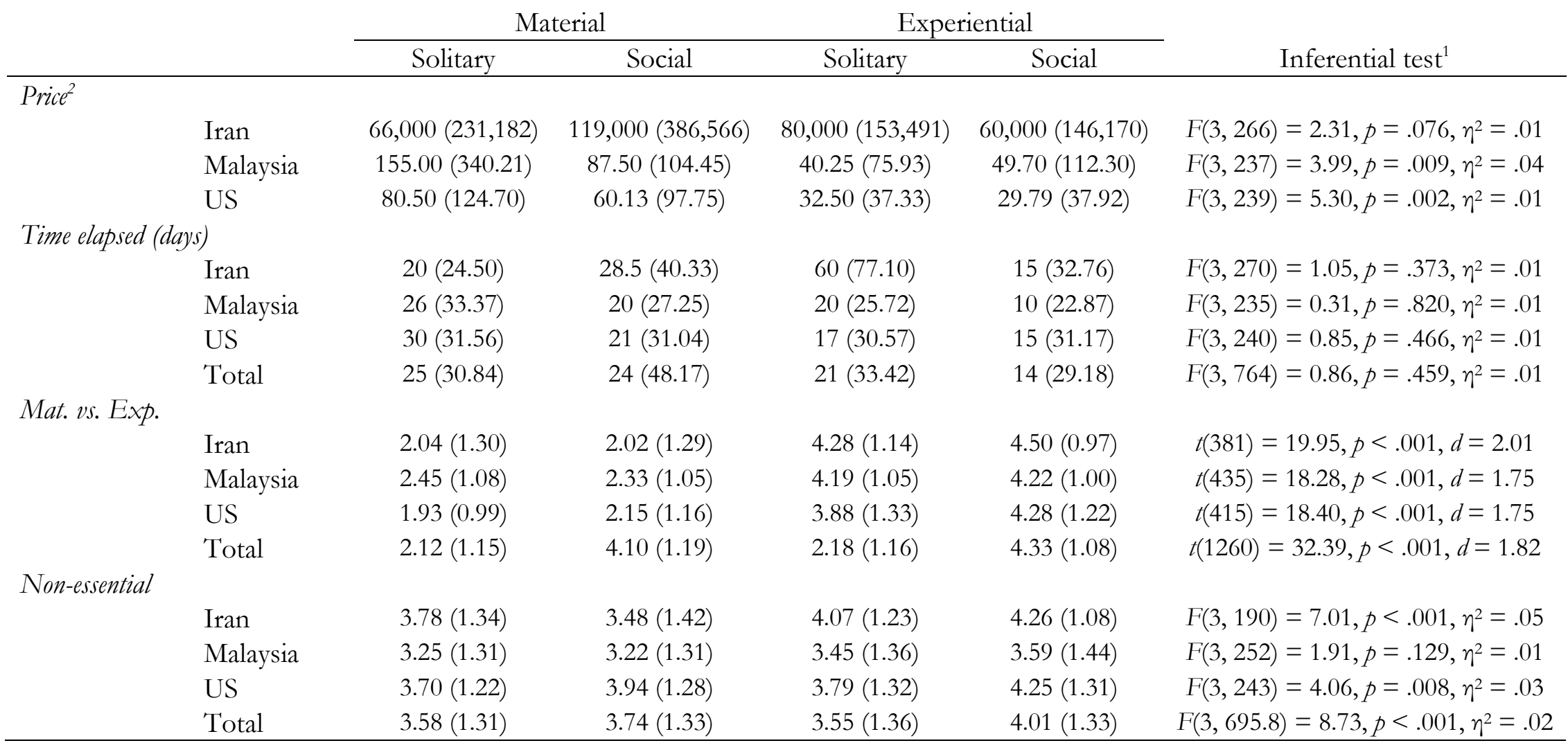

Notes. For the highly skewed variables (i.e., price and time elapsed), medians and Winsorized SDs (in parentheses) are reported. For the other variables, mean and SDs (in parentheses) are reported. Mat. vs. Exp. refers to participants' subjective continuous ratings of the purchase as a material or an experience. Non-essential refers to how much participants rate the purchase as essential or non-essential.

1 All tests are Welch's tests (not assuming equal variance). Welch's t-tests for the Mat. vs. Exp. ratings compare material and experiential purchases (collapsing across the solitary-social dimension) because this manipulation check item was intended for the comparison between those in the experiential (vs. material) groups.

${ }^{2}$ Prices are reported based on local currency (i.e., Toman for Iran, RM for Malaysia, and USD for the US). These three countries have different patterns of inflation and variability in consumer prices over time (The World Bank Data, 2019d), with Iran having a particularly high instability in consumer price indices and currency exchange rate over time (Aizenman, Chinn, \& Ito, 2013). Consequently, we refrain from converting the currencies and directly comparing them across countries. For examples of purchases in each country, see the Online Supplement. 
Material vs. Experiential. To examine the experiential advantage across outcomes, three linear mixed-effects models with different outcome variables were conducted using the R-package lme4 (Bates, Mäechler, Bolker, \& Walker, 2015). In each model, purchase type (material vs. experiential) and country (Iran, Malaysia, and US) were entered as the between-subjects and one of the three outcome categories (i.e., happiness, emotions, or evaluations) were entered as the withinsubjects (intercept nested within participants) predictors. Results of the contrast analyses (Table 4) demonstrate that Iranian participants assigned to the experiential purchase condition reported higher overall happiness, higher selffocused and other-focused positive emotions. None of these effects were present in Malaysia.
In the US, there was only a weak positive association between experiential purchases and positive other-focused emotions.

However, in all three samples, experiential purchases were positively associated with relational enhancement, and this was the largest effect observed within each country. Experiential purchases were positively associated with self-elevation among participants from Iran and Malaysia, but not the US. Overall, based on the comparison of these marginal means, the positive relationship between experiential (vs. material) purchases and relational enhancement is robustly replicated across countries. However, other associations seem to be smaller and culturespecific.

Table 4.

Comparison of Happiness, Emotions and Evaluations Associated with Material vs. Experiential Purchases

\begin{tabular}{|c|c|c|c|}
\hline & Iran & Malaysia & US \\
\hline \multicolumn{4}{|l|}{ Happiness } \\
\hline Instant happiness & $0.00[-0.30,0.29]$ & $-0.03[-0.34,0.29]$ & $-0.09[-0.41,0.23]$ \\
\hline General happiness & $0.54[0.24,0.83]$ & $0.24[-0.07,0.56]$ & $-0.16[-0.48,0.16]$ \\
\hline \multicolumn{4}{|l|}{ Emotions } \\
\hline Positive self-focused & $0.37[0.19,0.54]$ & $0.10[-0.10,0.29]$ & $0.11[-0.09,0.31]$ \\
\hline Positive other-focused & $0.40[0.22,0.57]$ & $0.15[-0.04,0.35]$ & $0.20[0.01,0.40]$ \\
\hline \multicolumn{4}{|l|}{ Evaluations } \\
\hline Self-elevation & $0.71[0.51,0.92]$ & $0.27[0.06,0.49]$ & $0.19[-0.03,0.41]$ \\
\hline Relational enhancement & $0.86[0.66,1.06]$ & $0.55[0.33,0.76]$ & $0.61[0.39,0.83]$ \\
\hline
\end{tabular}
Notes. In all models, the purchase type predictor was coded as Material $=-1$ and Experiential $=1$. Unstandardized $b$ coefficients and their 95\%CI [in brackets] are presented here. Confidence intervals were adjusted using a multivariate exact Tukey method correcting for the number of tests in each family within each country. Estimates in bold have $p<.05$. Pattern of results remain the same when controlling for price or time elapsed since purchase (see https://osf.io/n39gj/). 


\section{Comparison of the four purchase} types. Similar to the previous analyses, three linear mixed-effects models were run to test the association between purchase type and the three outcomes. The only difference here was that instead of two levels (material vs. experiential), the purchase type variable consisted of all the four categories, therefore taking into account the solitary-social dimension. Follow-up multiple comparison tests (using Holm-Bonferroni correction) were conducted to examine the difference between categories within each country. Detailed results are presented in Table 5 and Figure 1.

In short, results indicated no differences between purchase categories in terms of instant happiness, and only small differences in terms of general happiness. Unexpectedly, among the US participants, material-solitary purchases were associated with higher general happiness compared to material-social purchases.

For affiliative outcomes (i.e., otherfocused positive emotions and relational enhancement), a consistent trend was observed across countries, with participants in the experiential-social condition reporting the highest positive outcome, and those in the material-solitary condition reporting lowest, or one of the lower, positive outcomes. As one would expect, within each broader purchase category (i.e., material vs. experiential), social purchases were positively associated with affiliative outcomes across all countries. However, it is noteworthy that even among the social purchases, experiential ones were associated with more positive outcomes compare to material purchases, suggesting that the experiential advantage might be due to some unique aspect beyond the social nature of experiences.
The results were less consistent crossculturally in terms of the self-focused outcomes. An interesting effect was observed among the Iranian sample such that experiential-solitary purchases (compared to other categories) were associated with the highest self-elevation cognitions. Furthermore, this category elicited stronger self-focused emotions compared to both solitary and social materials. A different trend was observed for Malaysia and the US such that the differences were generally small and non-significant; importantly, the experiential-social advantage over material-solitary was only observed for self-elevation among Malaysian participants. These findings suggest that purchase results vary cross-culturally when measuring selfrelated outcomes, and they are not always consistent with the experiential advantage hypothesis. 
Table 5.

Descriptive Results and Multiple Comparisons of Outcomes Associated with Each Purchase Type in Each Country

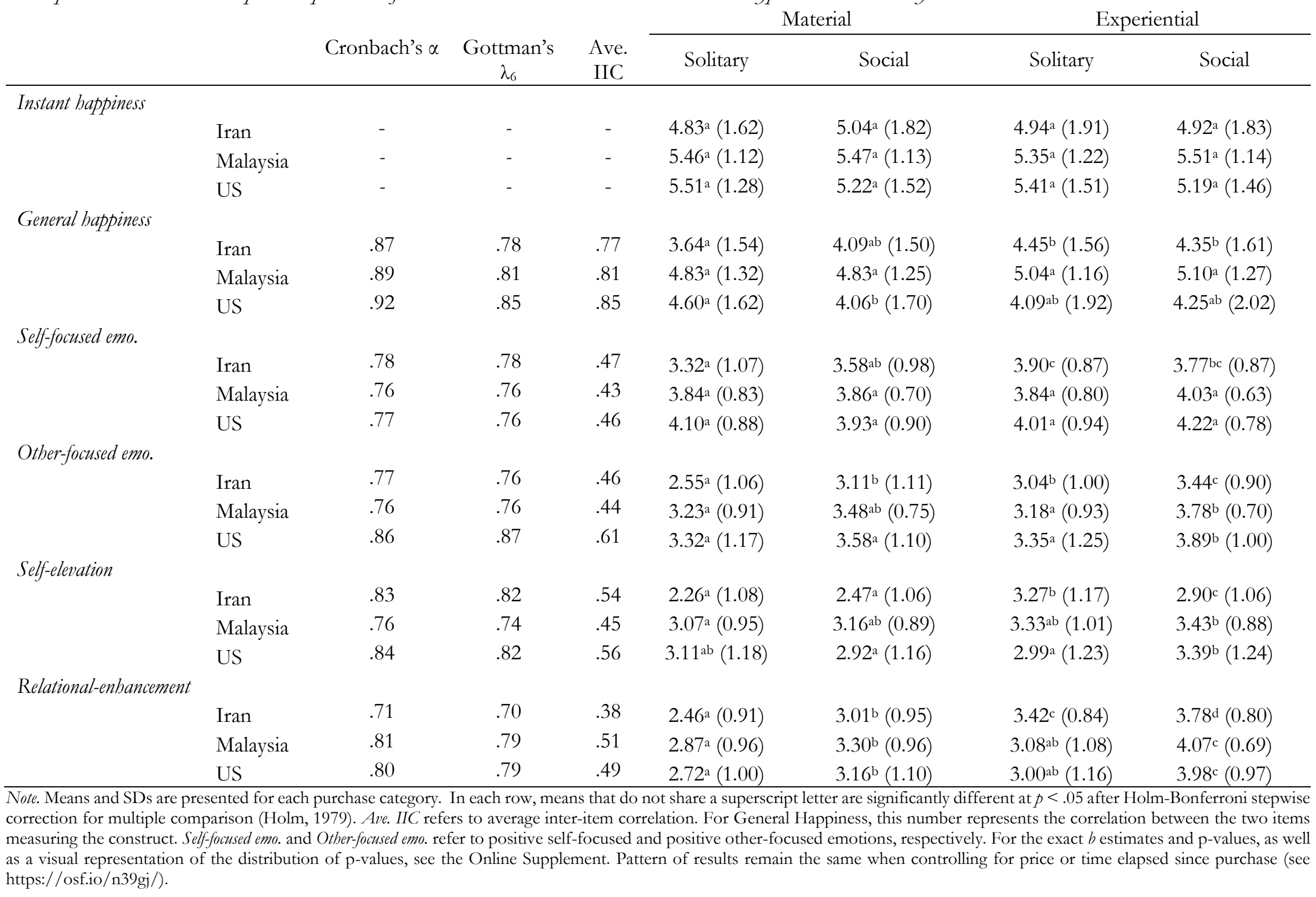




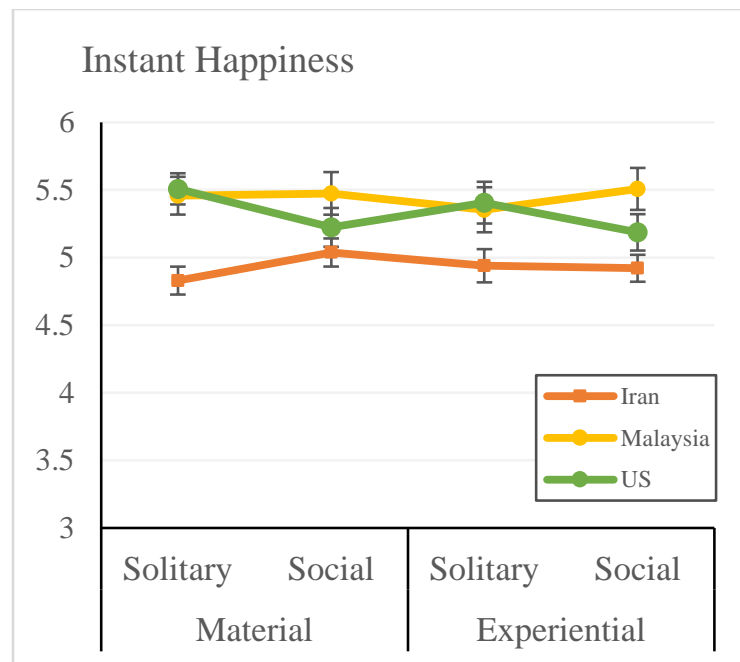

General Happiness

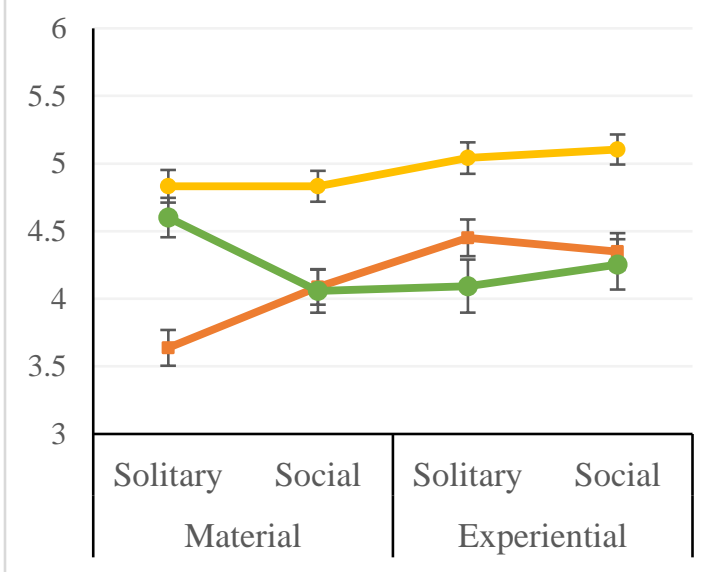

Positive Self-focused Emotions

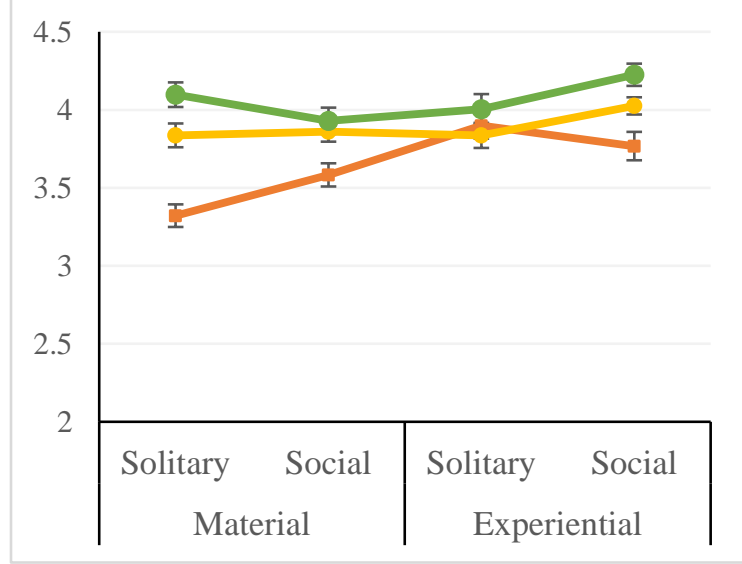

Positive Other-focused Emotions

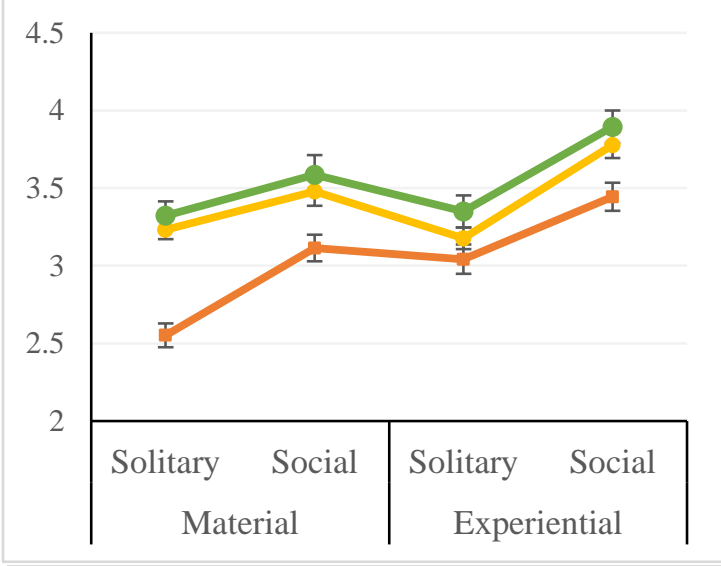

\section{Self-elevation}

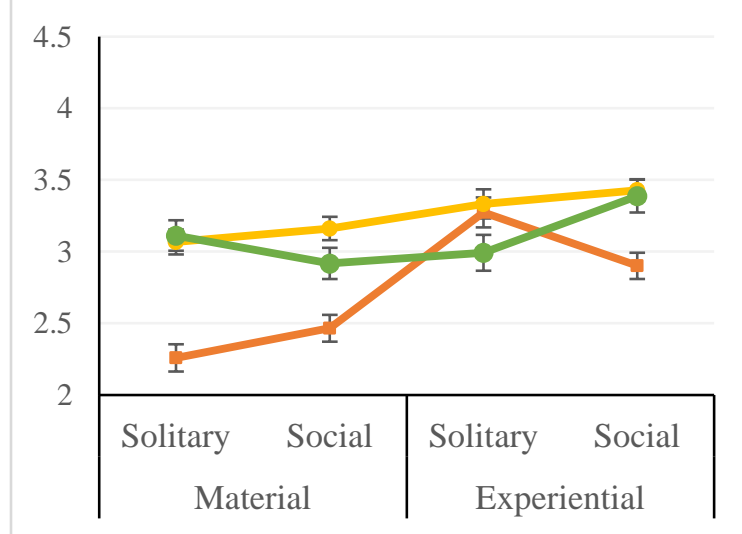

\section{Relational Enhancement}

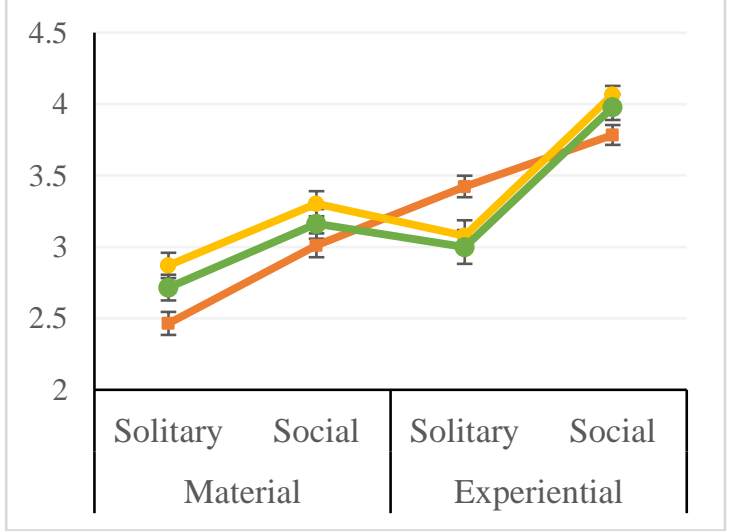

Figure 1. Differences between purchase types across countries.

Note. Error bars are standard errors. The theoretical range of responses for the happiness outcomes (top two panels) is one to seven; for the remaining outcomes, the range is one to five. 


\section{Discussion}

Results from three diverse samples suggest that the benefits associated with different types of purchases are cross-culturally consistent in some domains, and culturespecific in others. The link between experiential purchases and social outcomes, such as positive other-focused emotions and relational enhancement, consistently replicated across cultures and were the largest effects within each sample. Specifically, across these cultures, experiential-social purchases led to better social outcomes compared to other types, including material-social purchases, suggesting that there are unique benefits to experiences beyond their social nature. In contrast, results were less consistent when it came to happiness, self-focused emotions, and self-elevation.

To our knowledge, prior to this study the majority of the literature on experiential spending was based on Western samples. The present study was an initial step in testing the generalizability of the experiential advantage beyond WEIRD samples. While cognizant of the experiential buying literature and crosscultural theories of self and well-being, our approach to cross-cultural differences at this initial stage followed what Rozin (2001) described as "disciplined description or exploration of the phenomenon" (p. 5). We believe this approach is both necessary and fruitful for future theory development; and the results corroborate this notion. While we found cross-culturally robust relational benefits associated with experiential purchases, we were also able to detect an interesting culture-specific outcome in Iran.

Among Iranians, results demonstrated an unexpected advantage associated with the experiential-solitary purchases-Iranian participants reported relatively stronger positive self-focused emotions and selfelevation associated with experiential-solitary purchases. This is consistent with Caprariello and Reis' (2013; study 2) finding that people with stronger preference for solitude ranked solitary experiences higher than social ones. A qualitative review of the Iranian participants' narratives revealed a theme in which some participants explicitly expressed an appreciation for solitude, a tendency that is also reflected in Iranian art (e.g., Forouzani, 2015) and media (e.g., "Why is solitude beneficial?", 2016, December 21). Considering the cultural variability in preference for solitude (e.g., Van Zyl, Dankaert, \& Guse, 2018), a possible explanation for the observed self-focused results of solitary-experiential purchases among Iranians can be the higher preference for solitude in this culture. This is a potentially important finding because it points out a unique advantage of experiences - in addition to fulfilling the need for relatedness when they are shared with others, experiences may also fulfill the desire for voluntary solitude, especially in cultural contexts where solitude is valued. This conclusion requires future research.

\section{Limitations and Future Directions}

The present research had several limitations. First, to compare different purchase types, we used a common methodology in which participants were instructed to recall a past purchase. We controlled two dimensions of the purchase (i.e., material-experiential, and solitary-social) methodologically. However, it is likely that the purchases recalled by the participants vary systematically in other dimensions. This is a potential threat to internal validity and weakens the case for making causal claims. As such, we 
encourage caution against causal interpretation of the results. Second, the samples vary in age and education; any between-sample differences should be interpreted with this caveat in mind. Third, the ad-hoc measure of cognitive evaluations is novel and needs further tests of validity.

Finally, for theoretical reasons explained before, our approach to the culture-specific findings was descriptive. As such, the post-hoc explanations provided for the observed differences should be treated with caution. While the present results provide valuable insights, to make stronger inferences, confirmatory preregistered research in the future is needed (Srivastava, 2018, November 21). Furthermore, future research can benefit from linkage studies (Matsumoto \& Yoo, 2006) that examine the role of constructs such as materialism, access to resources, and preference for solitude as the active ingredients driving the differences in purchase outcomes.

\section{Footnotes}

1. To investigate whether the attrition rates were related to the experimental condition, observations were classified as incomplete (i.e., cases that did not complete any of the last four items before demographics) vs. complete (those who responded to at least one the last four items). Chi-square test of independence revealed that dropout rates were not conditional on the type of purchase participants were assigned to, $\chi^{2}(3, n=670)=2.26, p=.520$.

2. Telegram is a popular social network platform in Iran with polls estimating its penetration rate to be as high as $80 \%$ (Jafari, 2017).

3. To avoid exceptionally expensive or uncommon purchases, we provided a price range in the instructions. In each country, the lower boundary was the local movie ticket price and the upper boundary was a medium- to high-end Windows laptop. Due to substantial inflation during the data collection in Iran, the upper boundary was adjusted based on weekly prices.

4. Exclusion decisions were made using a dataset that only included participants' condition and their narrative. 


\section{References}

Adler, N., \& Stewart, J. (2007). The MacArthur scale of subjective social status. MacArthur Research Network on SES Health. Retrieved from http://www.macses.ucsf.edu/Research/Psychosocial/subjective. php.

Aizenman, J., Chinn, M. D., \& Ito, H. (2013). The 'Impossible Trinity' hypothesis in an era of global imbalances: Measurement and testing. Review of International Economics, 21(3), 447-458.

Arnett, J. J. (2008). The neglected 95\%: why American psychology needs to become less American. American Psychologist, 63(7), 602-614.

Bates, D. M., Mäechler, M., Bolker, B., \& Walker, S. (2015). Fitting linear mixed-effects models using lme4. Journal of Statistical Software, 67(1), 1-48.

Caprariello, P. A., \& Reis, H. T. (2013). To do, to have, or to share? Valuing experiences over material possessions depends on the involvement of others. Journal of Personality and Social Psychology, 104(2), 199-215.

Carter, T. J., \& Gilovich, T. (2010). The relative relativity of material and experiential purchases. Journal of Personality and Social Psychology, 98(1), 146-159.

Carter, T. J., \& Gilovich, T. (2012). I am what I do, not what I have: The differential centrality of experiential and material purchases to the self. Journal of Personality and Social Psychology, 102(6), 1304-1307.

Church, A.T., Katigbak, M.S., Locke, K.D., Zhang, H., Shen, J., Vargas-Flores, J.d.J., ... and Ching, C.M. (2013) Need satisfaction and well-being: Testing self-determination theory in eight cultures. Journal of Cross-Cultural Psychology, 44 (4). 507-534.

Deci, E. L., \& Ryan, R. M. (1985). The general causality orientations scale: Self-determination in personality. Journal of Research in Personality, 19, 109-134.

Diener, E., Oishi, S., \& Lucas, R. E. (2003). Personality, culture, and subjective well-being: Emotional and cognitive evaluations of life. Annual Review of Psychology, 54, 403-425.

Dienes, Z. (2008). Understanding psychology as a science: An introduction to scientific and statistical inference. Basingstoke, England: Palgrave Macmillan.

Dunn, E. W., Gilbert, D. T., \& Wilson, T. D. (2011). If money doesn't make you happy, then you probably aren't spending it right. Journal of Consumer Psychology, 21(2), 115-125.

Dunn, E. W., \& Weidman, A. C. (2015). Building a science of spending: Lessons from the past and directions for the future. Journal of Consumer Psychology, 25(1), 172-178.

Faul, F., Erdfelder, E., Buchner, A., \& Lang, A.-G. (2009). Statistical power analyses using G*Power 3.1: Tests for correlation and regression analyses. Behavior Research Methods, 41(4), 1149-1160.

Forouzani, S. A. G. (2015). An expressionistic survey in oriental aestheticism: The application of expressionism on a sample iranian ghashghaei rug. Buletin Teknol Tanaman, 13, 23-28.

Gelfand, M. J., Raver, J. L., Nishii, L., Leslie, L. M., Lun, J., Lim, B. C., ... \& Aycan, Z. (2011). Differences between tight and loose cultures: A 33-nation study. Science, 332(6033), 1100-1104.

Guimond, S., Branscombe, N. R., Brunot, S., Buunk, A. P., Chatard, A., Désert, M., ... \& Yzerbyt, V. (2007). Culture, gender, and the self: Variations and impact of social comparison processes. Journal of Personality and Social Psychology, 92(6), 1118-1134. 
Hamblin, J. (2014, October 7). Buy experiences, not things. The Atlantic. Retrieved from https://www.theatlantic.com

Hassaskhah, J., \& Jahedi, F. (2015). Role of social comparison orientation and tendencies in Iranian EFL learners academic achievement. Journal of Teaching Language Skills, 33(4), 45-65.

Hejazi, E., Salehnajafi, M., \& Amani, J. (2015). The mediating role of intrinsic motivation on the relationship between basic psychological needs and life satisfaction. Contemporary Psychology, 9(2), 77-88.

Helliwell, J., Layard, R., \& Sachs, J. (2018). World Happiness Report 2018. New York: Sustainable Development Solutions Network.

Henrich, J., Heine, S. J., \& Norenzayan, A. (2010). The weirdest people in the world? Behavioral and Brain Sciences, 33(2-3), 61-83.

Hofstede, G., Hofstede, G. J., \& Minkov, M. (2010). Cultures and organizations: Software of the mind. Revised and Expanded 3rd Edition. New York: McGraw-Hill.

Holm, S. (1979). A simple sequentially rejective multiple test procedure. Scandinavian Journal of Statistics, 6(2), 65-70.

Howell, R. T., \& Hill, G. (2009). The mediators of experiential purchases: Determining the impact of psychological needs satisfaction and social comparison. The Journal of Positive Psychology, 4(6), 511-522.

Impett, E. A., Gordon, A. M., Kogan, A., Oveis, C., Gable, S. L., \& Keltner, D. (2010). Moving toward more perfect unions: daily and long-term consequences of approach and avoidance goals in romantic relationships. Journal of Personality and Social Psychology, 99(6), 948-963.

IPSOS (2013. December 13). Global attitudes on materialism, finances, and family. Retrieved from https://www.ipsos.com/sites/default/files/news_and_polls/2013-12/6359.pdf

Jafari, H. (2017, June 18). Infographic: State of internet \& social media usage in Iran. Techrasa. Retrieved from http://techrasa.com/2017/06/18/infographic-state-internet-social-mediausage-iran/

Ji, L. J., Nisbett, R. E., \& Su, Y. (2001). Culture, change, and prediction. Psychological Science, 12(6), 450456.

Johnston, M. M., \& Finney, S. J. (2010). Measuring basic needs satisfaction: Evaluating previous research and conducting new psychometric evaluations of the Basic Needs Satisfaction in General Scale. Contemporary Educational Psychology, 35(4), 280-296.

Joshanloo, M. (2018). Optimal human functioning around the world: A new index of eudaimonic wellbeing in 166 nations. British Journal of Psychology, 109(4), 637-655.

Joshanloo, M., \& Gebauer, J.G. (in press). Religiosity's nomological network and temporal change: Introducing an extensive country-level religiosity index based on Gallup World Poll data. European Psychologist.

Joshanloo, M., \& Weijers, D. (2014). Aversion to happiness across cultures: A review of where and why people are averse to happiness. Journal of Happiness Studies, 15(3), 717-735.

Joshanloo, M., Weijers, D., Jiang, D. Y., Han, G., Bae, J., Pang, J. S., ... \& Khilji, I. A. (2015). Fragility of happiness beliefs across 15 national groups. Journal of Happiness Studies, 16(5), 1185-1210.

Kashdan, T. B., \& Breen, W. E. (2007). Materialism and diminished well-being: Experiential avoidance 
as a mediating mechanism. Journal of Social and Clinical Psychology, 26(5), 521-539.

Kasser, T. (2016). Materialistic values and goals. Annual Review of Psychology, 67, 489-514.

Kito, M., Yuki, M., \& Thomson, R. (2017). Relational mobility and close relationships: A socioecological approach to explain cross-cultural differences. Personal Relationships, 24(1), 114130.

Koo, J., \& Suh, E. (2015). Why Korean university students are less happy than U.S. counterparts? The role of relative extrinsic value orientation, social support and social comparison. The Korean Journal of Social and Personality Psychology, 29(4), 63-83.

Lebergott, S. (1993). Pursuing happiness: American consumers in the twentieth century. Princeton, N.J.: Princeton University Press.

Lee, J. C., Hall, D. L., \& Wood, W. (2018). Experiential or material purchases? Social class determines purchase happiness. Psychological Science, 29(7), 1031-1039.

Matsumoto, D., \& Yoo, S. H. (2006). Toward a new generation of cross-cultural research. Perspectives on Psychological Science, 1(3), 234-250.

Markus, H. R., \& Kitayama, S. (1991). Culture and the self: Implications for cognition, emotion, and motivation. Psychological Review, 98(2), 224-253.

Mauss, I. B., Savino, N. S., Anderson, C. L., Weisbuch, M., Tamir, M., \& Laudenslager, M. L. (2012). The pursuit of happiness can be lonely. Emotion, 12(5), 908-912.

Mayo, D. G. (2010). Learning from error severe testing, and the growth of theoretical knowledge. In: D. Mayo \& A. Spanos (Eds.), Error and inference. Cambridge: Cambridge University Press.

Medin, D., Ojalehto, B., Marin, A., \& Bang, M. (2017). Systems of (non-) diversity. Nature Human Behaviour, 1(5), 0088.

Mehran, G. (1989). Socialization of schoolchildren in the Islamic Republic of Iran. Iranian Studies, 22(1), 35-50.

Millar, M., \& Thomas, R. (2009). Discretionary activity and happiness: The role of materialism. Journal of Research in Personality, 43(4), 699-702.

Nicolao, L., Irwin, J. R., \& Goodman, J. K. (2009). Happiness for sale: Do experiential purchases make consumers happier than material purchases? Journal of Consumer Research, 36(2), 188-198.

Norenzayan, A., \& Heine, S. J. (2005). Psychological universals: What are they and how can we know? Psychological Bulletin, 131(5), 763-784.

Oishi, S., Graham, J., Kesebir, S., \& Galinha, I. C. (2013). Concepts of happiness across time and cultures. Personality and Social Psychology Bulletin, 39(5), 559-577.

Ong, D. O. L. , Kamaruddin, A. K. , Bulathsinhalage, C. N., \& Seneviratne, L. A. (2013). The influence of materialistic and ethical values on the purchase intention of counterfeit luxury goods: The case of Malaysian undergraduate. Journal of Marketing Research \& Case Studies, 2013, 1-17.

Pandelaere, M. (2016). Materialism and well-being: the role of consumption. Current Opinion in Psychology, 10, 33-38.

Pchelin, P., \& Howell, R. T. (2014). The hidden cost of value-seeking: People do not accurately forecast the economic benefits of experiential purchases. The Journal of Positive Psychology, 9(4), 322-334.

Pflug, J. (2009). Folk theories of happiness: A cross-cultural comparison of conceptions of happiness 
in Germany and South Africa. Social Indicators Research, 92(3), 551-563.

Pozin, I. (2016, March 3). The secret to happiness? Spend money on experiences, not things. Forbes. Retrieved from https://www.forbes.com

Puteh, A. (2010). The language medium policy in Malaysia: A plural society model? Review of European Studies, 2(2), 192-200.

Rozin, P. (2001). Social psychology and science: Some lessons from Solomon Asch. Personality and Social Psychology Review, 5(1), 2-14.

Salari Rad, M. S., Martingano, A. J., \& Ginges, J. (2018). Toward a psychology of Homo sapiens: Making psychological science more representative of the human population. Proceedings of the National Academy of Sciences, 115(45), 11401-11405.

Saucier, G., Kenner, J., Iurino, K., Bou Malham, P., Chen, Z., Thalmayer, A. G., ... \& Altschul, C. (2015). Cross-cultural differences in a global "survey of world views". Journal of Cross-Cultural Psychology, 46(1), 53-70.

Schwartz, S. H. (1994). Are there universal aspects in the structure and contents of human values? Journal of Social Issues, 50(4), 19-45.

Schwartz, S. H. (2006). A theory of cultural value orientations: Explication and applications. Comparative Sociology, 5, 136-182.

Srivastava, S. (2018, November 21). Sound Inference in Complicated Research: A Multi-Strategy Approach. https://doi.org/10.31234/osf.io/bwr48

Suh, E. M. (2000). Self, the hyphen between culture and subjective well-being. In E. Diener \& E. M. Suh (Eds.), Culture and subjective well-being (pp. 63-86). Cambridge, MA: MIT Press.

The World Bank Data (2019a). GDP (current US\$) [Data file]. Retrieved from http:/ /api.worldbank.org/v2/en/indicator/NY.GDP.PCAP.CD?downloadformat=excel

The World Bank Data (2019b). Education [Data file]. Retrieved from http:/ /api.worldbank.org/v2/en/topic/4?downloadformat=excel

The World Bank Data (2019c). Households and NPISHs Final consumption expenditure per capita (constant $2010 \quad$ US $\$$ ) [Data file]. $\quad$ Retrieved from http://api.worldbank.org/v2/en/indicator/NE.CON.PRVT.PC.KD?downloadformat=exc el

The World Bank Data (2019d). Inflation, consumer prices (annual \%) [Data file]. Retrieved from http://api.worldbank.org/v2/en/indicator/FP.CPI.TOTL.ZG?downloadformat=excel

Uchida, Y., \& Kitayama, S. (2009). Happiness and unhappiness in East and West: Themes and variations. Emotion, 9(4), 441-456.

Uchida, Y., Kitayama, S., Mesquita, B., Reyes, J. A., \& Morling, B. (2008). Is perceived emotional support beneficial? Well-being and health in independent and interdependent cultures. Personality and Social Psychology Bulletin, 34(6), 741-754.

Usborne, S. (2017, May 13). Just do it: The experience economy and how we turned our backs on 'stuff.' The Guardian. Retrieved from https://www.theguardian.com

Uz, I. (2015). The index of cultural tightness and looseness among 68 countries. Journal of Cross-Cultural Psychology, 46(3), 319-335.

Van Boven, L., \& Gilovich, T. (2003). To do or to have? That is the question. Journal of Personality and Social Psychology, 85(6), 1193. 
Van Zyl, C. J., Dankaert, E., \& Guse, T. (2018). Motivation for solitude: A cross-cultural examination of adolescents from collectivist and individualist cultures in South Africa. Journal of Child and Family Studies, 27(3), 697-706.

Veillard, N. (2017). WEIRD sampling in cross-cultural psychology, should it not be less WEIRD and more representative? (Unpublished master's thesis). Leiden University, Leiden, Netherlands.

West, S. G., \& Sagarin, B. J. (2000). Participant selection and loss in randomized experiments. In L. Bickman (Ed.), Research design: Donald Campbell's legacy (pp. 117-154). Thousand Oaks, CA: SAGE Publications.

"Why is solitude beneficial?" (2016, December 21). Retrieved from https://www.eghtesadonline.com/n/nHY

Wong, N., Rindfleisch, A., \& Burroughs, J. E. (2003). Do reverse-worded items confound measures in cross-cultural consumer research? The case of the material values scale. Journal of Consumer Research, 30(1), 72-91.

Zhang, J. W., Howell, R. T., Caprariello, P. A., \& Guevarra, D. A. (2014). Damned if they do, damned if they don't: Material buyers are not happier from material or experiential consumption. Journal of Research in Personality, 50, 71-83. 